\title{
Preliminary noise assessment of aircraft with distributed electric propulsion
}

\author{
Athanasios P. Synodinos* and Rod H. Self ${ }^{\dagger}$ and Antonio J. Torija \\ University of Southampton, Southampton, England SO17 1BJ, United Kingdom
}

\begin{abstract}
Electric and hybrid-electric propulsion technologies in aviation are becoming more attractive for aviation stakeholders not only due to the resulting reduction or elimination of the dependency on oil, whose availability and price are uncertain, but also because they are more reliable and efficient than traditional internal combustion engines. Moreover, combined with distributed electric propulsion (DEP), these technologies have shown potential in significantly reducing civil aircraft community noise impact and contribute towards delivering the strict mid-to-long-term environmental goals set by organisations worldwide, such as ACARE and NASA. This paper examines the noise impact of a concept tube and wing aircraft that falls in the A320 category and features various DEP systems using different power supply units (turboshaft engines or batteries) and number of electric propulsors. Meanwhile, considerations required for the transition from conventional to electric propulsion are discussed. Estimated Noise-Power-Distance (NPD) curves and noise exposure contour maps are also presented. It is concluded that indeed, the propulsors' number is a key parameter for optimising the environmental performance of DEP aircraft and hence maximising the noise benefits. Also, it is shown that based on the entry into service year (2035) technology, totally electric aircraft tend to have a larger noise footprint than aircraft using hybrid electric propulsion systems.
\end{abstract}

\section{Introduction}

In response to the potential environmental impacts of the projected air traffic growth over the next few years [1, 2], several organisations worldwide elaborated challenging interim-to-long-term environmental targets. For instance, ACARE's Flightpath 2050 [3] envisions at cutting down aircraft noise by $65 \%$, NOx emissions by $95 \%$ and $\mathrm{CO}_{2}$ emissions by $75 \%$ with respect to the performance of year 2000 civil aircraft. NASA technology targets for their N+3 timeframe (year 2030) are equally aggressive [4]. Delivering these targets requires radical changes in aircraft design involving new structures, advanced configurations and innovative propulsion systems.

Electric propulsion is anticipated as one of the most suitable and reliable propulsion systems for powering future civil aircraft that could satisfy the aforementioned environmental targets [4]. This is because: a) it can eliminate aviation combustion emissions and phase out dependency on oil, and b) power inverters in electric systems offer total independence between generator and propulsors shaft speeds, providing not only efficiency benefits (e.g. optimum fan speed ratios for particular flight circumstances), but also abundant design possibilities and propulsion configurations that have potential to reduce propulsive aircraft noise [5].

One such possibility is Distributed Electric Propulsion (DEP) i.e. the thrust dispersion among numerous electric propulsors, that, in addition to its noise-related potential benefits offers numerous advantages [6]. The most prominent ones, independently of vehicle design (i.e. traditional tube-and-wing or unconventional concepts, such as Blended Wing Body (BWB) aircraft) and DEP architecture (i.e. power supply type, propulsors layout, etc.) are:

- Electric fans can be scaled down, in contrast to gas turbine engines that contain non-scalable parts, offering potential of reducing the propulsion system weight (as shown later in Figure 6.

- Multiple smaller fans are easier to integrate into an aircraft and mounted at suitable locations for exploiting benefits associated with e.g. Boundary-Layer Ingestion (BLI) [7, 8] and noise shielding.

- Electric fans can be powered directly by batteries, facilitating the path towards totally electric civil aviation.

This paper presents preliminary noise impact estimations for a concept tube-and-wing DEP aircraft that falls in the A320 category. The concept DEP aircraft is referred to in this paper as e-A320 because it uses the A320 fuselage along with an array of electric propulsors. So essentially the turbofans on a A320 are replaced by a DEP system, as illustrated

\footnotetext{
*Visiting academic, Institute of Sound and Vibration Research, a.synodinos@ soton.ac.uk.

${ }^{\dagger}$ Professor, Institute of Sound and Vibration Research.

${ }^{\ddagger}$ Senior research fellow, Institute of Sound and Vibration Research.
} 


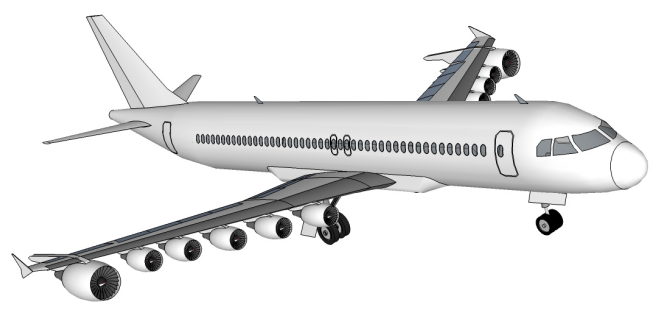

Fig. 1 Schematic representation of the examined e-A320 when the DEP array consists of 10 electric propulsors driven by 2 turboshaft engines located on each wing tip. The airframe is that of the baseline A320.

in the sketches of Figures 1 and 2. Different e-A320 variants (termed e-A320s) are examined featuring different power supply units (turboshaft engine(s) or batteries) and number of electric propulsors, as described in Section $\Pi$ Design and performance parameters for the e-A320s, most importantly their weight and thrust requirements, that are necessary inputs to the employed noise assessment framework, are estimated. Although this introduces uncertainty due to the various assumptions made (that are inevitable in this early development stage of electric aircraft), it offers an excellent opportunity to mention and discuss the considerations necessary for the transition from traditional internal combustion engines to electric propulsion.

\section{II. e-A320 aircraft configurations under investigation}

The e-A320 examined in this study is assumed to have entry into service (EIS) planned for the year 2035 and mission characteristics similar to current short/medium-haul aircraft. That is a range capacity of $900 \mathrm{~nm}$, complying with the results of market demand analysis performed by Bauhaus Luftfahrt [9], and identical passenger capacity to the conventional A320, i.e. 150 passengers.

Among numerous candidate DEP architectures [6, 10], the two most commonly encountered in DEP aircraft prototypes in literature are: a) Turbo-Electric propulsion (TeDP) where electric propulsors are powered by one or more turboshaft engines, and b) All-Electric propulsion, where power is exclusively generated by batteries. This paper presents noise assessments for e-A320 featuring either of these architectures. Moreover, the effect of varying the number of electric propulsors is investigated for both architectures.

Figure 2 (a) shows the component chain of a TeDP system. A generator converts the mechanical power from the turboshaft to electrical, which is then supplied to the electric motors that drive the fans. The TeDP system can use either conventional (i.e. kerosene) or advanced (e.g. hydrogen) fuel. Overall, although this architecture exploits benefits of distributed propulsion, it does not eliminate the generation of combustion emissions. Representative aircraft concepts that use the TeDP architecture are the NASA N3-X [4] and the ESAero TeDP [11].

The component chain of a DEP All-Electric system is illustrated in Figure 2(b). The array of electric propulsors is directly powered by batteries. An example of an All-Electric aircraft is NASA's X-57 Maxwell [5] concept aircraft that is envisioned to be powered only by batteries.

\section{A. Electric Propulsors dimensions}

Electric propulsors maximum diameter is constrained to $2 \mathrm{~m}$ by the baseline A320 height. Moreover, in accordance with TeDP design studies in literature [] the minimum possible propulsors fan diameter is set at $0.35 \mathrm{~m}$. Table 1 shows geometry information of the various DEP arrays examined. The performance data in Table 1 are based on the efan propulsor [12] and engine performance trends in references [13, 14]. Rated thrust is based on the thrust requirements for the e-A320s estimated in Section IV Fan speed is based on trends of gas turbine engines that have no gearbox. As earlier stated power inverters can be used as an efficient gearbox in electric propulsion, optimising fan speed.

\section{B. Estimation of nacelle surface area}

The nacelle area, $S_{n c l}$, is required for weight estimations in the following sections. While it increases with fan diameter, its complex shape makes accurate calculations difficult. Although $S_{n c l}$ could be approximated through several semi-analytical methods [15], estimating its relationship with fan diameter fulfils the scope of the present analysis. Hence, the nacelle is considered as a body of revolution, most conveniently a cylinder, without the inlet and outlet areas. 


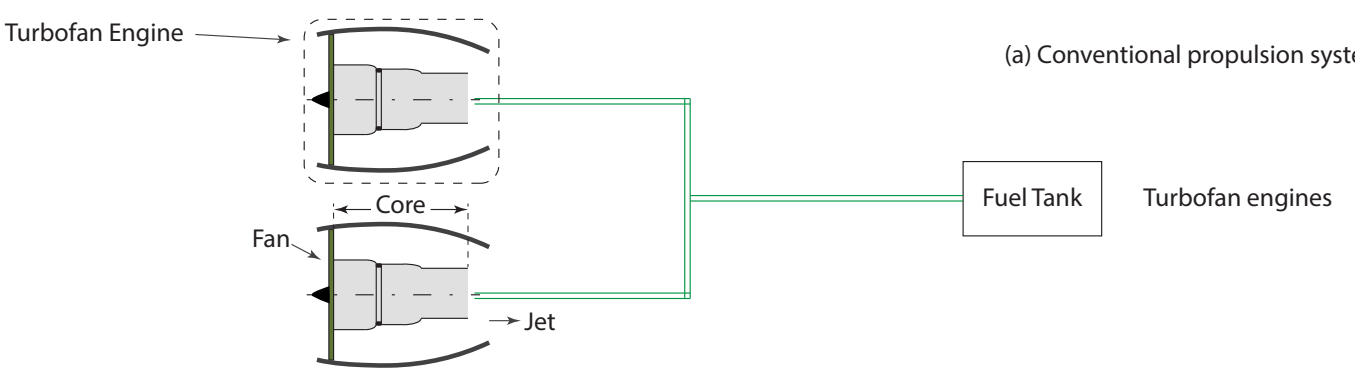

(b) DEP systems:

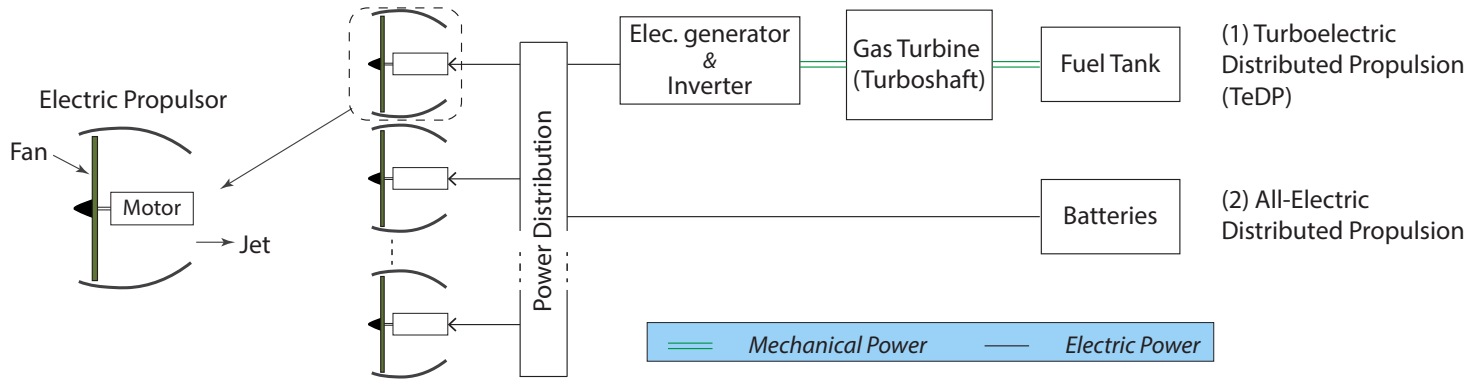

Fig. 2 Components chain schematic of (a) Conventional propulsion system, (b) DEP systems used in this study.

Table 1 Estimated performance data for the electric propulsors used in this study and A320 data.

\begin{tabular}{l|c|cccccc} 
Aircraft type & A320 & \multicolumn{7}{|c}{ DEP Aircraft } \\
\hline Number of propulsors & 2 & 2 & 4 & 6 & 8 & 10 & 12 \\
Fan diameter (m) & 1.61 & 2.01 & 1.43 & 1.01 & 0.72 & 0.51 & 0.36 \\
Airflow (kg/s) & 355 & 506 & 248 & 171 & 132 & 101 & 76.7 \\
Fan speed (rpm) & 5650 & 4321 & 6120 & 8665 & 12271 & 17377 & 24606 \\
Rated thrust (kN) & 117 & 134 & 64.5 & 43.4 & 32.3 & 24.6 & 19.4
\end{tabular}

That cylinder's dimensions are defined through the turbofan engine sketch of Figure 3. The minimum and maximum nacelle cross-section areas are denoted $d_{\min }$ and $d_{\max }$ respectively. It is assumed that the fan diameter equals the inlet diameter, i.e. $d_{f}=d_{i n}$. According to Kroo [16], the inlet cross section area, $A_{i n} \approx 0.7 A_{\max }$; hence $d_{\max } \approx 1.2 d_{i n}$. Also, it is assumed that the nacelle's average diameter is $d_{a v}=1.1 d_{f}$. Finally, historical trends deriving from publicly available aviation databases (e.g. the ICAO ANP Database [17], the EASA Type Certificates (TCDS) [13] and the Jet Engine Specification Database [14]) imply that roughly, the conventional turbofan engines length $\ell \approx 1.7 d_{f}$. A smaller estimate of $\ell \approx 1.5 d_{f}$ is adopted for the electric propulsors to account for the fact that it only consist of a fan and motor.

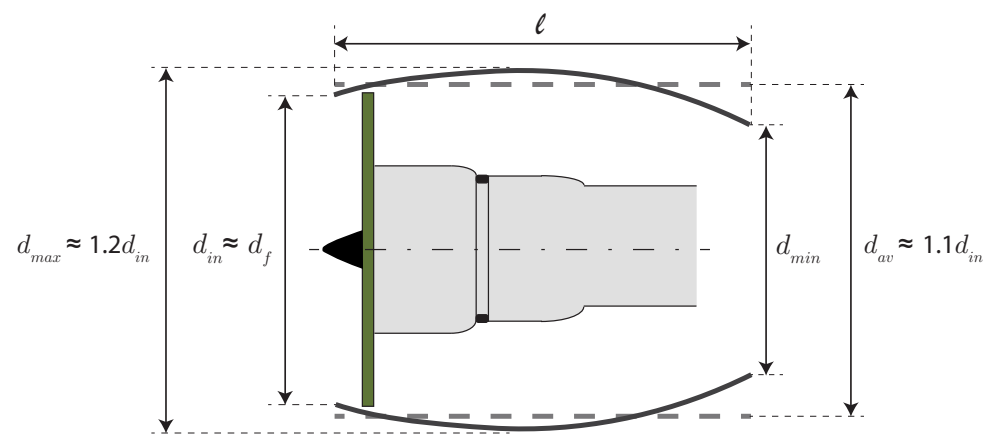

Fig. 3 Approximation of turbofan nacelle shape as a cylinder of diameter $d_{a v}$ and length $\ell$. 
Based on these approximations, the nacelle is represented by a cylinder of equivalent area with diameter $d_{a v}$ and length $\ell$. Thus, the nacelle surface area is the cylinder's area minus the inlet and outlet surfaces:

$$
S_{n c l} \approx 1.1 \pi d_{f} \ell \approx 1.87 \pi d_{f}^{2} .
$$

\section{Establishment of required parameters for the e-A320s noise impact assessment}

\section{A. Methodology overview}

Noise impact assessment of the e-A320s is performed using the noise prediction framework for novel aircraft designs proposed by Synodinos et al.[18]. In summary, the framework estimates aircraft noise variation arising from operational and/or technological changes with respect to a baseline scenario for which community noise is known. As specified in [18], this is done by first estimating the level change of each aircraft noise source using dedicated, publicly available noise prediction methods (e.g. Heidmann [19] for fan, or Guo for krueger flaps [20] ). The framework is purely computational, which allows forecasting impacts of future scenarios while bypassing the need for noise measurements and/or proprietary data.

In the study presented in this paper, the baseline scenario is the default takeoff and approach fight profiles of a conventional A320 for which noise and performance data are publicly available (e.g. in the ANP database [17]). Moreover, it is assumed that the e-A320s perform the same (i.e. the default) takeoff and approach trajectories as the A320. Noise benefits from optimised flight profiles are beyond the scope of this study, but can be easily incorporated into the framework proposed by Synodinos et al. [18]. Essentially, replacing the turbofans on an A320 by DEP arrays induces aircraft weight changes. These lead into thrust requirement and high-lift device settings changes that in turn generate noise variations. Hence overall, it is required to define the noise sources on the e-A320s and assess the thrust requirements of the different variants.

\section{B. Noise sources on the e-A320}

Noise sources on the e-A320 aircraft are the power generator, the electric propulsors and the airframe. The latter is mainly determined by the states of the landing gears and high lift devices and is therefore significant during approach. The noise contribution of the power generator is assumed negligible for both DEP architectures. In an all-electric aircraft, this is due to the low noise features of battery systems. Whereas turboshaft engines in TeDP systems are normally designed to produce minimum thrust and hence have small exhaust velocity and reduced exhaust noise impact. Turboshafts fan noise could be notable but it is neglected in this study considering that novel aircraft are likely to have their turboshafts buried within the aircraft and/or exploit their airframe for shielding noise sources.

Although future aircraft are expected to exploit environmental benefits of BLI technologies, these are not considered in the examined e-A320. This is because BLI is a relatively new technology that requires a specialised design, which goes beyond the scope of the present paper. It must be mentioned though that BLI is likely to introduce a new noise source that can be assumed to be non-dominant because: a) BLI noise is related to the fan interaction with the non-uniform inlet flow and hence is likely to be a narrowband or tonal noise that could be attenuated with liners (that would however affect the aircraft weight), and b) BLI noise will probably be shielded by the airframe.

As shown in Figure 2, the electric propulsors consist of a fan, a jet and a motor. The motor noise contribution is presumed negligible, based on predictions in [21], leaving only the jet and fan as propulsors' significant noise sources. Thus, the noise prediction methods employed in the noise prediction framework by Synodinos et al.[18] are Heidmann's [19] for the fan, Fink's [22] for the airframe and Lighthill's acoustic analogy [23] for the jet.

\section{Thrust requirements for the e-A320 variants}

Normally, aircraft thrust requirements are either publicly available (e.g. in [17] for existing civil aircraft) or provided by stakeholders interested in noise assessments and/or design parametric studies (e.g. manufacturers, designers, etc.). Alternatively they can be calculated through dedicated tools, but this requires knowledge of detailed aircraft design and performance parameters. Complying with this study's aims, thrust requirements for the e-A320s are estimated.

Altering the baseline A320 propulsion system (i.e replacing the turbofan engines by DEP systems) is likely to affect its total weight and drag, and consequently, its thrust requirements. Moreover, the number of propulsors within the DEP system plays a crucial role, because it determines not only the propulsors size (and hence their weight, drag and aircraft thrust requirements), but also the engine noise spectral content. The propulsors' number also influences the minimum 
thrust requirements per propulsor, $F_{p, \min }(N)$, as dictated by safety regulations. Under these considerations, if a turbofan engine generating thrust $F$ is replaced by an array of $N$ propulsors, the gross thrust provided by each propulsor is given by a function

$$
F_{p}=\frac{F+\Delta F_{D}+\Delta F_{W}}{N},
$$

with

$$
F_{p} \geqslant F_{p, \min }(N),
$$

where $\Delta F_{D}, \Delta F_{W}$ represent the thrust variation due to drag and weight alterations respectively. The next sections describe procedures for determining $F_{p, \min }(N)$ and estimating the variations $\Delta F_{D}, \Delta F_{W}$ in Equation 2

\section{A. Safety considerations}

According to the FAR 25 [24] airworthiness regulations for multiengine aircraft, the minimum engine thrust of conventional twin or quad engine aircraft is dictated by the one engine out condition. This represents the necessity of the aircraft to be capable of meeting the climb demands, under several circumstances, with one engine inoperative. So denoting $F_{c l m b}$ the maximum climb thrust required by a $N$ engine aircraft, the minimum thrust provided by each engine should be

$$
F_{p, \text { min }}=\frac{F_{c l m b}}{N-n},
$$

where $n$ is the number of inoperative engines; for conventional aircraft, $n=1$. Quantity $F_{c l m b}$ is mainly determined by the MTOW and can be estimated through the SAE-AIR 1845 procedures [25].

Equation 3 suggests that $F_{p, \min }$ becomes smaller than $F_{c l m b}$ as the number of engines increases; this is because the thrust loss due to one engine failure decreases with number of engines. Clearly, the mandatory excessive amount of thrust produced per engine for safety reasons decreases with number of engines, implying that DEP configurations can lead to reducing efficiency losses due to safety constraints.

Meanwhile, increasing the number of engines also raises the probability of one engine failing, implying that the FAR 25 one engine out condition is unsuitable for DEP aircraft. If the probability of one propulsor failure is $\mathcal{P}$, with $\mathcal{P}<<1$ then the probability of one propulsor failing among $N$ propulsors is $\mathcal{P} N$. The probability of multiple propulsors failing during a single flight is dramatically smaller; assuming that the events of each propulsor failure are independent of each other (this may not be a totally realistic assumption, since these events could be a result of a common cause) then according to the binomial distribution, the probability of $n$ propulsors becoming inoperative is

$$
\mathcal{P}_{n}=\left(\begin{array}{l}
N \\
n
\end{array}\right) \mathcal{P}^{n}(1-\mathcal{P})^{(N-n)},
$$

where the binomial coefficient

$$
\left(\begin{array}{l}
N \\
n
\end{array}\right)=\frac{N !}{(N-n) ! n !} .
$$

Since $\mathcal{P}<<1$, it is apparent that $\mathcal{P}_{n}$ is $n$ orders of magnitude smaller than $\mathcal{P}$. Normally, failure probability $\mathcal{P}_{n}$ increases with flight duration but this influence is considered negligible in this study and is not included in Equation 4

Overall, increasing propulsors' number results into reducing the safety-related minimum required thrust per propulsor while increasing the probability of one propulsor failing. These contradicting behaviours reveal that minimum required propulsor's thrust in DEP systems must be determined through different processes. Since this topic is irrelevant to the present study, it is assumed in a simplified way that the maximum accepted failure probability is $\mathcal{P}_{n}=0.001 \%$ and hence the number of concurrently inoperative propulsors $n$ must be adjusted as seen in Table 2 . Using values of that Table, the thrust $F_{p, \min }$ can be obtained from Equation 3 .

\section{B. Drag considerations}

All e-A320 variants use the fuselage of the baseline A320 and consequently, assuming fixed airspeed, drag differences between the A320 and the e-A320s emerge from dissimilarities of propulsion systems geometry. Civil aircraft aerodynamic drag breakdowns in references [26, 27] suggest that skin-friction drag is insignificant during takeoff and landing, where lift-induced drag clearly dominates. It becomes important during cruise, where it comprises about half the total aircraft drag, but still, engine drag is small compared to the wing and body drag. Therefore, drag variation with fan diameter and number of propulsors has negligible effect on the whole aircraft thrust requirements and is not included in this study (i.e. in Equation $2, \Delta F_{D} \approx 0$ ), although it can be promptly estimated. 
Table 2 Number of inoperative propulsors out of $N$, if accepted failure probability is $\mathcal{P}_{n}=0.001 \%$.

\begin{tabular}{cc}
\hline $\begin{array}{c}\text { No of propulsors } \\
N\end{array}$ & $\begin{array}{c}\text { No of concurrent inoperative } \\
\text { propulsors satisfying } \mathcal{P}_{n}=0.001 \% \\
n\end{array}$ \\
\hline 2 to 4 & 1 \\
5 to 6 & 2 \\
7 to 36 & 3 \\
37 to 60 & 4 \\
\hline
\end{tabular}

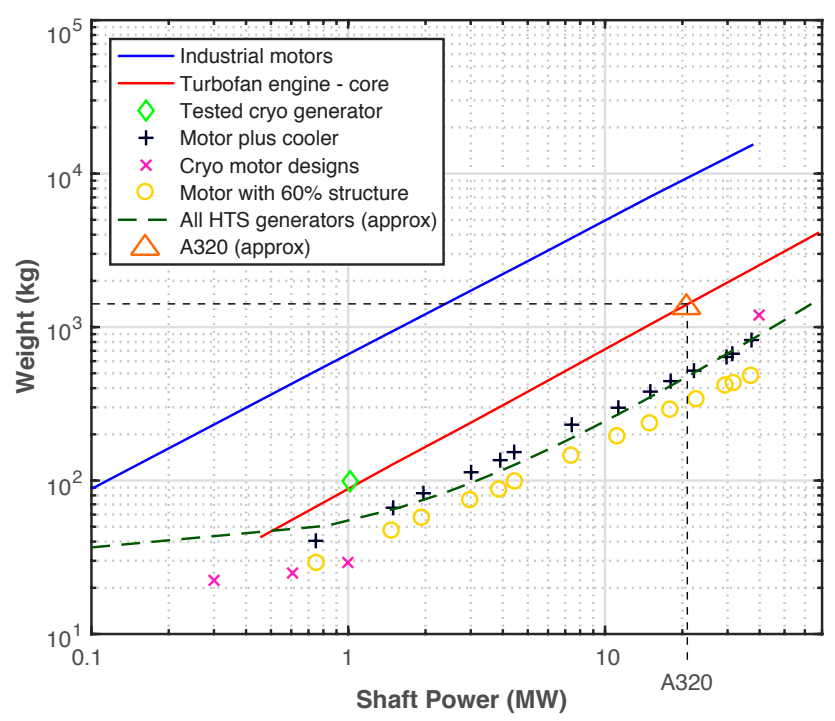

Fig. 4 Weights of various types of turbofan cores, motors and HTS generators as functions of power, based on future technological expectations. The plot is reproduced based on reference [6].

\section{Weigh considerations}

This section estimates the weight difference between the baseline A320 and the various e-A320 versions. Considering that the fuselage geometry is kept unchanged, any potential weight variation for the e-A320s arises from differences in the power system (e.g. turboshaft engine or batteries) and number of electric propulsors.

\section{Weight of baseline A320 turbofan engines}

Figure 4 is reproduced based on reference [6] and depicts estimated weight of turbofan cores, as well as of different electric generator and motor types as a function of shaft power. It is possible to appraise the core weight of the baseline A320 turbofans from that Figure, if the A320 power requirements are known.

The maximum power is drained during takeoff and hence power requirements are established based on the takeoff phase configuration. Maximum power is

$$
P_{\max }=N V_{c} F_{\infty},
$$

where the A320 takeoff speed $V_{c}=84 \mathrm{~m} / \mathrm{s}$, is calculated through the SAE-AIR 1845 procedures [25]. The rated thrust, $F_{\infty}=117 \mathrm{kN}$, is used rather than the net takeoff thrust $F_{N}$ (at takeoff engines normally operate just below its rated thrust) because the power should cover the event of requiring $100 \%$ of thrust.

The A320 maximum power requirements are estimated at 19.7 MW. It can be presumed that an extra $5 \%$ of power is provided for various other reasons, yielding $21 \mathrm{MW}$. Hence, using Figure 4 , the total core weight (2 turbofans) is approximated at $1.5 \mathrm{t}$. Subtracting the core weight from the engine dry weight, which is $2.4 \mathrm{t}$ [13], yields the weight of the remaining engine components (i.e fan, lining). Moreover, the nacelle and pylon weight is approximately 0.6 times the engine dry weight [16], i.e. $1.44 \mathrm{t}$. Hence, the total weight (2 engines) of fan, nacelle (and pylon) and lining is $7.68 \mathrm{t}$. To account for the weight of miscellaneous components within the propulsion system, the total weight is rounded up to $8 \mathrm{t}$. 


\section{Fuel requirements of the $A 320$}

The baseline A320 fuel requirements for the $900 \mathrm{~nm}$ mission are appraised next. The Operating Empty Weight $(\mathrm{OEW})$ of the $\mathrm{A} 320$ is $42.2 \mathrm{t}$ [28], whereas for short-range trips, the average mass of a passenger with luggage is $100 \mathrm{~kg}$ [29], yielding an overall passenger weight of $15 \mathrm{t}$. The SFC at cruise is $0.596 \mathrm{lb} /(\mathrm{lbf} \cdot \mathrm{h})$ [14] and the airspeed is $0.78 \mathrm{M}$ at $37,000 \mathrm{ft}$ [28]. The cruise L/D ratio is approximately 15, as worked out from data in [30]. Using these inputs in the Breguet range equation [31], the fuel weight is approximated at $6 \mathrm{t}$. However, safety regulations [32] stipulate that reserve fuel must allow 45 minutes of flight. Since the A320 cruise fuel flow is $0.88 \mathrm{~kg} / \mathrm{s}$ [33], the reserve fuel weight should roughly be $3 \mathrm{t}$. Hence, it is assumed that the A320 should be equipped with $9 \mathrm{t}$ of fuel for the $900 \mathrm{~nm}$ mission.

\section{Weight of array of electric propulsors, $W_{p a}$}

Both examined e-A320 architectures (i.e. TeDP and the All-Electric) are conveniently assumed to use identical electric propulsors arrays, despite the later-shown thrust requirement differences between them (as pointed out elsewhere, optimising the propulsors performance goes beyond the scope of this paper). This section investigates the propulsors array weight variation with number of propulsors. This is achieved by decomposing the electric propulsor into its components (i.e. fan, nacelle, lining and motor) and estimating their weight variation with fan diameter, in conformance with Lolis et al. [34] findings described below.

Numerous methods are publicly available for predicting the weight of conventional gas turbine engines. A critical review of them is given by Lolis et al. [34], who classifies methods into whole engine based and component based. The former use public engine data to produce empirical equations that correlate the engine weight with one (thrust or mass flow) or more (fan diameter, BPR, OPR, etc.) design parameters. Component based methods compute analytically each component's weight using empirical data and numerous input variables. Lolis et al. [34] used existing methods to predict the weight of actual engines and despite observing notable discrepancies between results, they suggested that engine weight (and size) is mostly determined by the engine diameter, which is in turn established from the fan diameter. The below-derived analogies between fan diameter and components' weight involve some very crud approximations and serve for capturing the trends in DEP systems.

Motor weight:

According to Liu et al. [35], the motor weight is related with its power, $P_{m t r}$, in MW and shaft speed, $N 1$, in rpm as follows:

$$
W_{m t r}=2325 \sqrt{\frac{P_{m t r}}{N 1}} .
$$

It is sensible to assume that $P_{m t r}$ changes with the fan diameter, $d_{f}$, and hence, with the number of propulsors. Based on Liu et al. [35] the variation of propulsors power with fan diameter is assumed to have a quadratic nature as shown in the left plot of Figure 5. Also, afore-mentioned historical trends indicate that $N 1$ and fan diameter are related with a power function (see plot XX in Appendix XX).

Using the relationships $P_{m t r}\left(d_{f}\right)$ and $N 1\left(d_{f}\right)$ in Equation 7 yields the estimated variation between motor weight and number of propulsors that is illustrated in the right plot of Figure 5 .

Fan weight:

According to the component based method of Sagerser [36] the fan weight and fan diameter are related with

$$
W_{\text {fan }}=135 d_{f}^{2.7} .
$$

This relationship is assumed representative for the electric propulsors fans as well.

Nacelle and lining weight:

The weight of the nacelle and lining are estimated based on their thickness, $z$, surface area, $S_{n c l}$ and material density, $\rho$. Assuming that the treated area is $20 \%$ of the inner nacelle area, the nacelle and lining weight variation with fan diameter is approximately

$$
W_{n c l} \approx g S_{n c l}\left(\rho_{n} z_{n}+0.2 \rho_{l} z_{l}\right),
$$

where subscripts $n, l$ refer to the nacelle and liner. It is presumed that $z_{n}=1 \mathrm{~mm}, z_{l}=5 \mathrm{~mm}, \rho_{n}=2500 \mathrm{~kg} / \mathrm{m}^{3}$ (corresponding to duralumin [37]) and $\rho_{l}=9000 \mathrm{~kg} / \mathrm{m}^{3}$ (corresponding to Haynes 25 [38]).

Total weight of propulsors array:

The weight of one propulsor is the sum of its components weights, i.e.

$$
W_{p}=W_{m t r}+W_{f a n}+W_{n c l},
$$



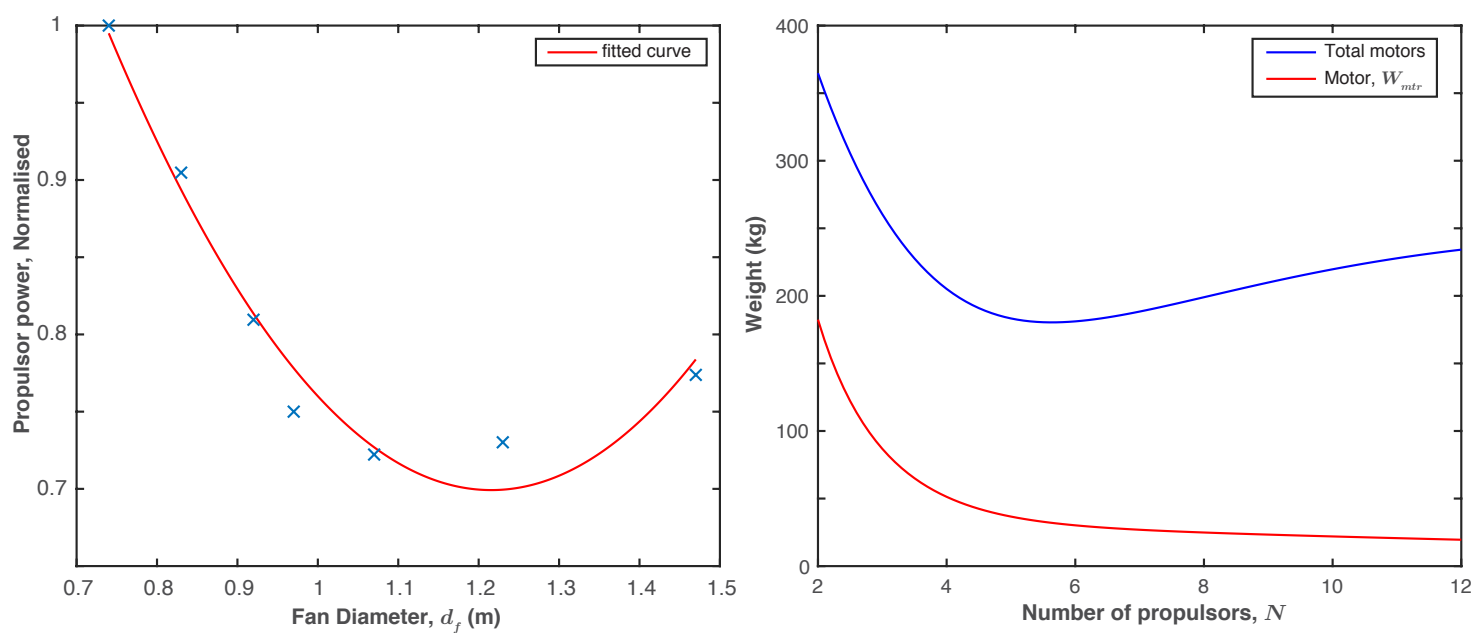

Fig. 5 Left: Propulsors power variation with fan diameter (based on [35]). Right: Estimated motor weight for different number of propulsors.

and hence, the propulsors array weight is

$$
W_{p a}=N W_{p} .
$$

The left diagram of Figure 6 depicts the propulsor weight variation with fan diameter. More interestingly, the right plot of the Figure shows that the total weight of the DEP array reduces while increasing the number of propulsors, implying that in terms of weight, it is beneficiary to seek the maximum possible number of propulsors, i.e. use the smallest possible propulsors. Similar behaviour was found by Liu et al. [35].
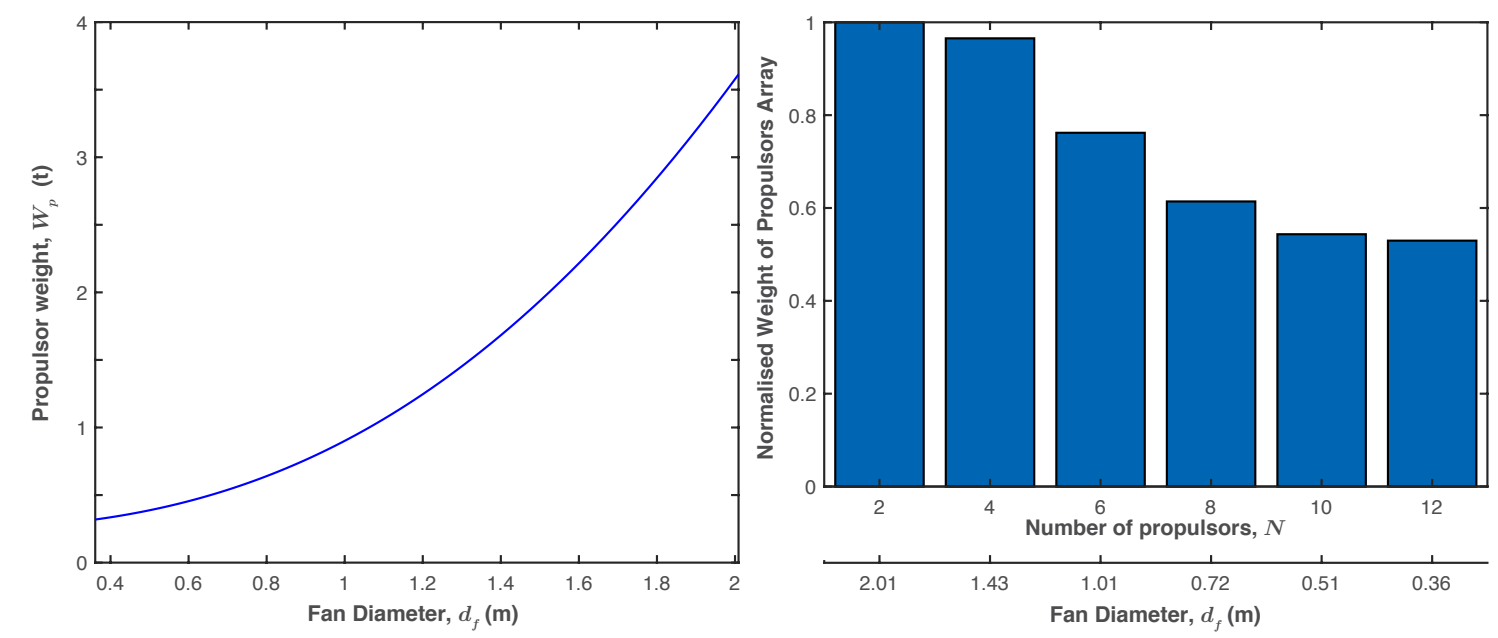

Fig. 6 Left: Relationship between fan diameter and propulsor weight. Right: Approximated effect of propulsors number on the DP array weight.

\section{Power supply weight, $W_{p w r}$}

The aircraft maximum power requirements, $P_{\max }$, determine the power supply unit specifications and weight. Equation 6 suggests that $P_{\max }$ is a function of takeoff speed and thrust; both quantities depend on MTOW, which is affected by the variation of the propulsors array weight with number of propulsors, indicating that $P_{\max }$ varies with $N$.

Also, power supply weight contributes to the aircraft MTOW creating the loop shown in Figure 7 Thus, assessing the power supply weight requires several iterations of calculations, until convergence, as shown later in this Section. It is sensible to assume that in the TeDP e-A320s the turboshaft weight is not sensitive to relatively small output power 
variations, due to the inability to fine-scale all its parts. This conclusion is also drawn from examining the turboshaft engine specification database [14]. Hence, the selection of turbogenerator type is assumed unrelated to the propulsors' number. In contrast, batteries weight in All-Electric e-A320s is determined from power requirements and therefore, the convergence loop is only used for this e-A320 architecture.

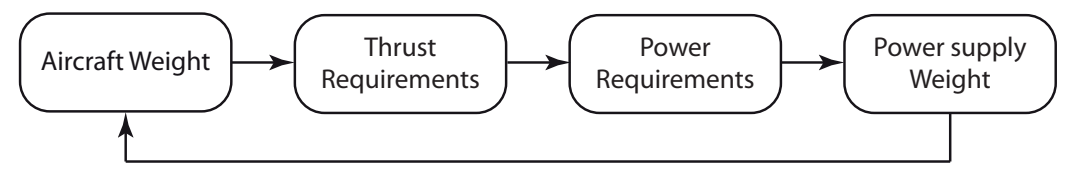

Fig. 7 Schematic of the loop describing the relationship between aircraft weight and power supply weight.

\section{Turboelectric $(\mathrm{TeDP})$ system}

Turbogenerator weight:

The turbogenerator consists of a turboshaft engine and a generator. An appropriate turbogenerator should cover the TeDP e-A320 power requirements that are assumed to be $23 \mathrm{MW}$, i.e. the requirements of the baseline A320 (i.e. $21 \mathrm{MW}$ ) plus an additional $10 \%$ due to electric system inefficiencies, as suggested in [39]. Still, this may be an overestimated value, since electric propulsors developments aim at notably reducing power consumptions, as implied by Hepperle et al. [40].

The turboshaft engine specification database [14] and reference [41] imply that a turboshaft delivering the required power, including the generator, weights around $2 \mathrm{t}$, independently of propulsors number (as described earlier). This weight reflects current technology and could possibly be less due to future technology improvements. In a simplified way, it is assumed that if 2 turboshafts are used (e.g. like in the prototype in Figure 1 , their total weight remains 2 t.

Power generator and inverter weight:

Figure 4 implies that all arrangements' weight increases with shaft power at roughly the same rate. For fixed power requirements the turbofan core is heavier than the motor or generator with its cooler. Accuracy on this weight difference is beyond the scope of the present study. Using Figure 4 the power generator weight, $W_{g n r}$, is about $300 \mathrm{~kg}$. In addition, based on estimated weights in [6] and [39], the inverter weight is approximately $W_{i n v} \approx 0.6 W_{g n r}$, i.e. $180 \mathrm{~kg}$.

Cabling weight:

DEP configurations are envisioned to feature super-conductive cables and High Temperature Superconducting (HTS) technologies to eliminate electric power transmission losses related to conventional cables resistance [42]. Hence, the cables' size is only a function of the energy to be transmitted and not a function of losses. Cabling diameter (and thus weight) increases with power requirements [43]. So based on propulsors power variation with fan diameter (see left plot of Figure 5) cabling weight, $W_{c b l} \propto P_{m t r}$. Influence of the thrust requirements variation with number of propulsors on the overall aircraft power requirements is trivial and is ignored, since it only adds unnecessary complexity to this study.

If the power generator is at fixed location and the propulsors are connected in series, cabling weight varies only with $P_{m t r}$. Hence, cabling weight variation will probably be insignificant compared to the whole aircraft weight and is disregarded. Alternatively, since $W_{c b l} \propto P_{m t r}$ and $W_{m t r} \propto P_{m t r}$ the effect of $W_{c b l}$ can be taken into account by increasing the motor weight by a small percentage, say $10 \%$. For completeness, this is the method adopted in this study.

Fuel weight:

In TeDP systems, the fuel weight is determined by the SFC of the turboshaft. Based on the turboshaft engine specification database [14] it is assumed that the TeDP e-A320 requires roughly the same amount of fuel as the A320-232, i.e 9 t. Yet, future turboshaft engines are likely to be more efficient and consume less fuel.

\section{All-Electric system}

In an All-Electric aircraft the propulsors are driven by batteries rather than by a turbogenerator. Although this eliminates the fuel tank requirement, the size and weight of the batteries introduce a new vital issue. A further concern is that All-Electric aircraft weight remains fixed across the whole flight, as there is no mass variation during flight due to fuel burn as in conventional aircraft. This is unrelated to this case study's calculations but should be generally considered, since it alters performance parameters affecting the cruise and landing flight phases.

Batteries:

The batteries' weight is inversely proportional to their specific energy, $e$ (i.e. energy stored per unit mass or volume). Figure 8 shows theoretical, practical and expected energy densities of various rechargeable battery types, as found in [40]. 
Also quoted is the effective specific energy of kerosene in combustion engines, which consists just the $14 \%$ of the raw kerosene fuel specific energy (which is around $12000 \mathrm{Wh} / \mathrm{kg}$ ), due to fuel burn inefficiencies. It is seen that Lithium-air (Li-O2) batteries have shown potential in reaching the specific energy of gasoline, however, their technology is in early development stages [4]. Clearly, realising even a modest range capability for electric aircraft requires technological breakthroughs that will significantly increase batteries' specific energy and reduce their weight and size [40]. Based on Figure 8 it is assumed that a specific energy of $1500 \mathrm{Wh} / \mathrm{kg}$ will have been reached by the target EIS of 2035 .

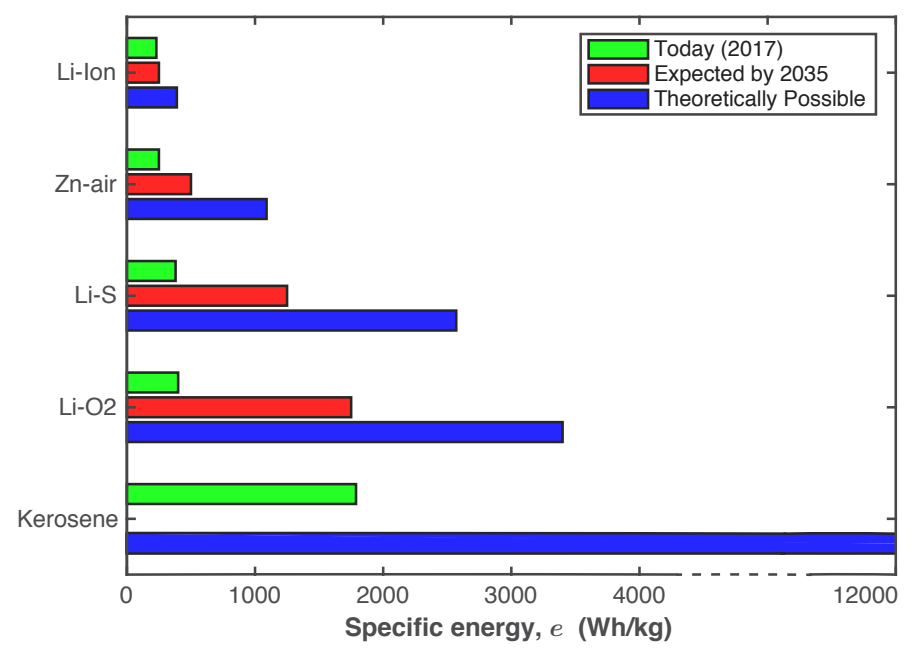

Fig. 8 Current, expected and theoretically possible specific energy for various types of batteries [40]. Effective and theoretically possible specific energy of kerosene in combustion engines is quoted for comparison [4].

Batteries weight estimation through convergence:

As previously described, batteries weight is estimated using a loop process until the values converge. The starting value for the peak power requirements is assumed to be that of the TeDP e-A320, i.e. $23 \mathrm{MW}$. As mentioned earlier, power requirements may reduce dramatically in the future as a result of reducing electric propulsors power consumption [40]. Comparing to the power and energy requirements for the Ce-Liner aircraft in [9], the minimum energy required by the All-Electric e-A320 with 2 propulsors for the $900 \mathrm{~nm}$ mission, including reserve requirements, is estimated at $32 \mathrm{MWh}$; in which case total weight of the batteries with specific energy of $1500 \mathrm{Wh} / \mathrm{kg}$ would be $W_{b t r}=23 \mathrm{t}$.

This battery weight is substituted in Equation 12 below to yield the aircraft weight, based on which the peak thrust (with Equation 14 below) and power requirements are re-calculated yielding a new batteries weight. The process is repeated until values converge, as in the left plot of Figure 9 . The right plot shows the variation of batteries weight with $N$, after convergence.

\section{Total aircraft weight, $W_{a c}$}

Table 3 shows breakdowns of the weights for the A320-232 and the e-A320 variants. Figure 10 shows the estimated total weight of the examined eA320s, at takeoff and approach, calculated with:

$$
W_{a c}=W_{p a}+W_{p w r}+O E W+\text { Payload } .
$$

While the TeDP aircraft is lighter in approach due to the fuel consumed throughout the flight, weight remains unchanged for the batteries-powered All-Electric aircraft. Hence, the latter is only represented by a single bar type (grey coloured) in Figure 10, whereas plain and dotted blue bars are used to denote the TeDP aircraft weight at takeoff and approach respectively. All the All-Electric variants are heavier than the baseline A320, due to the batteries' weight. TeDP variants with more than 4 propulsors are lighter than the A320.

\section{Thrust variation with number of propulsors}

Thrust requirements variation with propulsors' number can be directly calculated using the above-estimated eA320 weights (as mentioned earlier, drag effect is negligible). Thrust requirements are assessed under the assumption that all eA320s use the takeoff and approach flight profiles of the baseline A320. Clearly, flight profiles can be optimised based 

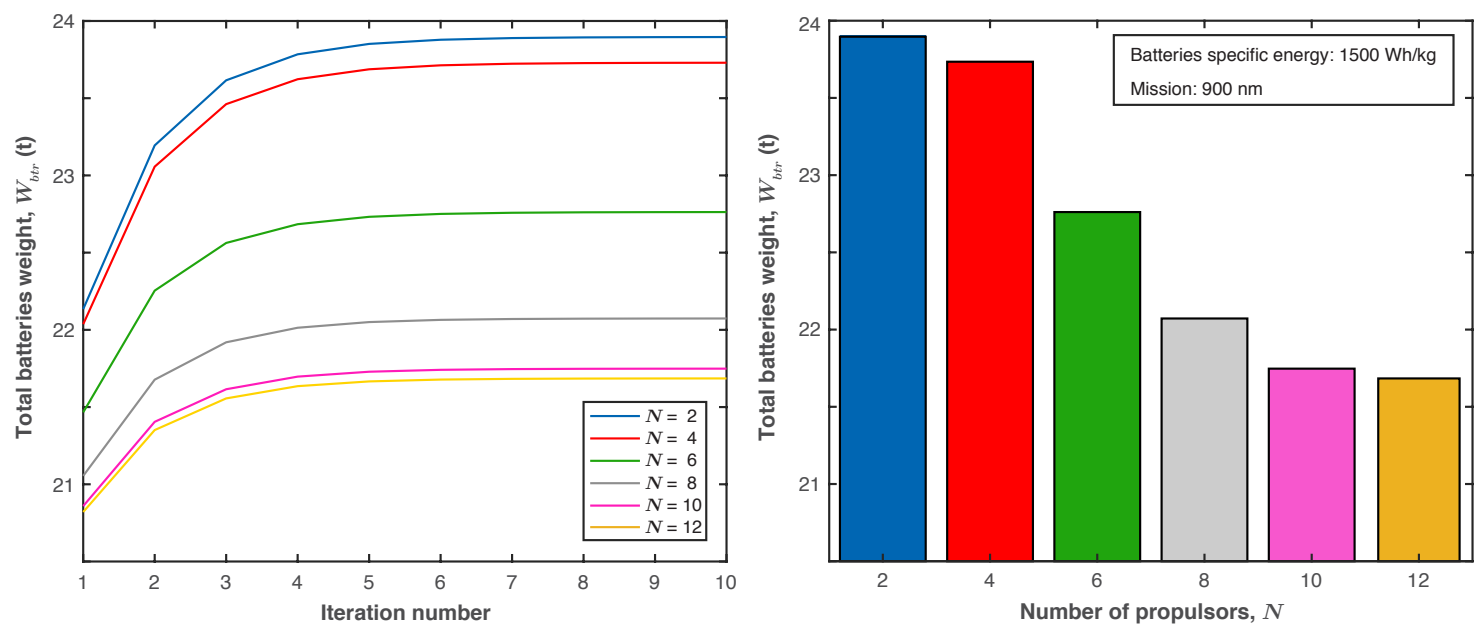

Fig. 9 Right: Total batteries weight for the $900 \mathrm{~nm}$ mission as function of propulsors number, as converged after the 10 iterations shown in the left plot.

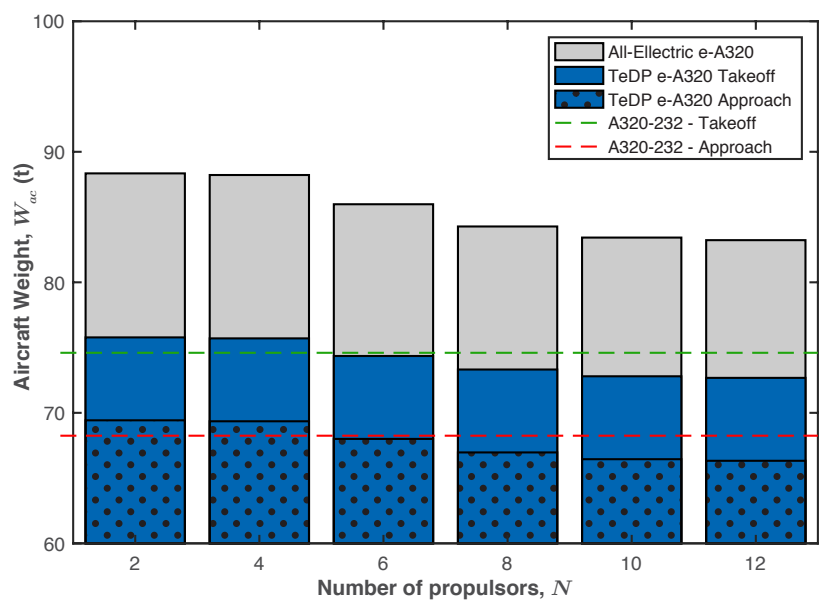

Fig. 10 Takeoff and landing weight of the examined e-A320s. The A320-232 weights are shown for comparison.

on each eA320 characteristics, affecting both thrust requirements and noise impacts. Likewise, flight profiles could have been obtained based on fixed thrust and varying takeoff and approach angles. Yet, these scenarios go beyond this study. Assuming negligible bank angle effects, SAE-AIR 1845 [25] appraises the average geometric climb angle with:

$$
\gamma=\arcsin \left[K\left(N \frac{\overline{F_{N} / \delta_{a m}}}{\overline{W / \delta_{a m}}}-\frac{R}{\cos \epsilon}\right)\right],
$$

where $R$ is the L/D ratio corresponding to a given flap setting, as given by ANP Database [17]. With $\delta_{a m}$ being the ratio of the ambient air pressure at the aircraft altitude to the standard pressure, $\overline{F_{N} / \delta_{a m}}$ is the corrected net thrust per engine. Constant $K$ depends on the airspeed. Hence, altering the aircraft weight from $W_{0}$ to $W_{0}+\Delta W$ induces a thrust requirements change

$$
\Delta F_{W}=F_{0} \frac{\Delta W}{W_{0}} .
$$

So, $\Delta F_{W}$, between the baseline A320 and the e-A320 variations, for takeoff and approach, is obtained by using the corresponding (takeoff or approach) baseline weight $W_{0}$ and thrust $F_{0}$, as shown next. 
Table 3 Weight breakdowns for the A320-232 and the e-A320 variants. Propulsion systems weights are estimated. Energy requirements are for a $900 \mathrm{~nm}, 150$ Pax mission at $0.78 \mathrm{M}$ and include safety reserve.

\begin{tabular}{|c|c|c|c|c|c|c|c|c|}
\hline \multirow{2}{*}{$\begin{array}{l}\text { Aircraft } \\
\text { System }\end{array}$} & \multicolumn{2}{|c|}{ A320-232 (Baseline aircraft) } & \multicolumn{3}{|l|}{ TeDP e-A320 } & \multicolumn{3}{|c|}{ All - Electric e-A320 } \\
\hline & Component & $\begin{array}{c}\text { Weight } \\
\text { (t) }\end{array}$ & Component & \multicolumn{2}{|c|}{ Weight (t) } & Component & \multicolumn{2}{|c|}{ Weight (t) } \\
\hline \multirow[t]{6}{*}{ Propulsion } & Core $(\mathrm{x} 2)$ & 1.5 & El. propuls. array & 3.83 & 7.22 & El. propuls. array & 3.83 & 7.22 \\
\hline & $\operatorname{Fan}^{\dagger}$, liners, other* $(x 2)$ & 3.3 & Turboshaft & \multicolumn{2}{|c|}{1.8} & & & \\
\hline & Engine Dry (x2) & 4.8 & Electric generator & \multicolumn{2}{|c|}{0.38} & & & \\
\hline & Nacelle + Pylon (x2) & 2.88 & Inverter & \multicolumn{2}{|c|}{0.18} & & & \\
\hline & $\operatorname{Misc}(\mathrm{x} 2)$ & 0.32 & & & & & & \\
\hline & Total Propulsion: & 8 & & 6.67 & 9.15 & & 4.49 & 6.97 \\
\hline \multirow[t]{2}{*}{ Payload } & $\begin{array}{l}\text { Fuel Tank } \\
\text { (incl. reserve) }\end{array}$ & 9 & $\begin{array}{l}\text { Fuel Tank } \\
\text { (incl. reserve) }\end{array}$ & \multicolumn{2}{|c|}{9} & $\begin{array}{l}\text { Batteries } \\
(e=1.5 \mathrm{kWhr} / \mathrm{kg})\end{array}$ & 21.7 & 23.9 \\
\hline & 150 Passengers & 15 & 150 Passengers & \multicolumn{2}{|c|}{15} & 150 Passengers & \multicolumn{2}{|c|}{15} \\
\hline \multirow[t]{2}{*}{ OEW } & & 42.6 & & \multicolumn{2}{|c|}{42.6} & & \multicolumn{2}{|c|}{42.6} \\
\hline & Total Aircraft: & 74.6 & & 72.6 & 76.0 & & 83.1 & 88.7 \\
\hline
\end{tabular}

* E.g. fuel and ignition systems, lubrication system, bleed air system, etc. [44]

$\dagger$ Includes LPT section [44]

\section{E. Takeoff}

Takeoff thrust per engine for the A32-232 is $F_{0}=112 \mathrm{kN}$, as calculated from the SAE-AIR 1845 [25] aircraft performance procedure. According to Table 3, weight $W_{0, T O}=74.6 \mathrm{t}$; whereas

$$
\Delta W_{T O}=W_{a c}-W_{0, T O} .
$$

Inserting these values in Equation 14 yields thrust requirements difference, $\Delta F_{W}$. The takeoff thrust per propulsor is then calculated with

$$
F_{p}=\frac{F_{0}+\Delta F_{W}}{N}
$$

and must satisfy the safety-related minimum thrust per engine, $F_{p, \text { min }}$, condition of Equation 3 and Table 2 . The climb thrust, $F_{\text {climb }}$, is assessed through the SAE-AIR 1845 procedure, by calculating that the baseline A320-232 can maintain a $5^{\circ}$ climb if $F_{\text {climb }, 0} \geqslant 58 \mathrm{kN}$. This baseline value is inserted in Equation 14 for obtaining the e-A 320 s climb thrust variation with:

$$
\Delta F_{\text {climb }}=F_{\text {climb }, 0} \frac{\Delta W}{W_{0}},
$$

where $\Delta W$ is the weight difference between the A320-232 and the e-A320 aircraft. Figure 11depicts the calculated takeoff thrust per propulsor, $F_{p}$, along with the associated $F_{p, \min }$, for both the TeDP and All - Electric e-A320s. The latter is heavier and hence has higher thrust requirements and $F_{p, \min }$ than the TeDP versions. Figure 11 shows that the condition $F_{p} \geqslant F_{p \text {, min }}$ is satisfied for all the cases examined. Figure 12 shows the resulting e-A320s thrust requirements as calculated with the SAE-AIR1845A procedure [25]. The green dashed line represents the baseline A320-232. As expected, the heavier All-Electric aircraft have more demanding thrust requirements than the TeDPs and the A320-232.

\section{F. Approach}

Approach thrust requirements are obtained similarly. Approach thrust per engine for the A32-232 is $F_{0}=16.4 \mathrm{kN}$ and approach weight is the takeoff weight minus the fuel consumed (as for the TeDP e-A320).

$$
W_{0, A P}=W_{0, T O}-W_{\text {fuel }} .
$$

In contrast, the All-Electric e-A320 weight remains the same throughout the mission, since no fuel is burnt. Hence:

$$
\Delta W_{A P}= \begin{cases}\left(W_{a c}-W_{f u e l}\right)-W_{0, A P}=\Delta W_{T O}, & \text { for TeDP e-A320, } \\ W_{a c}-W_{0, A P}=\Delta W_{T O}-W_{f u e l}, & \text { for All-Electric e-A320. }\end{cases}
$$



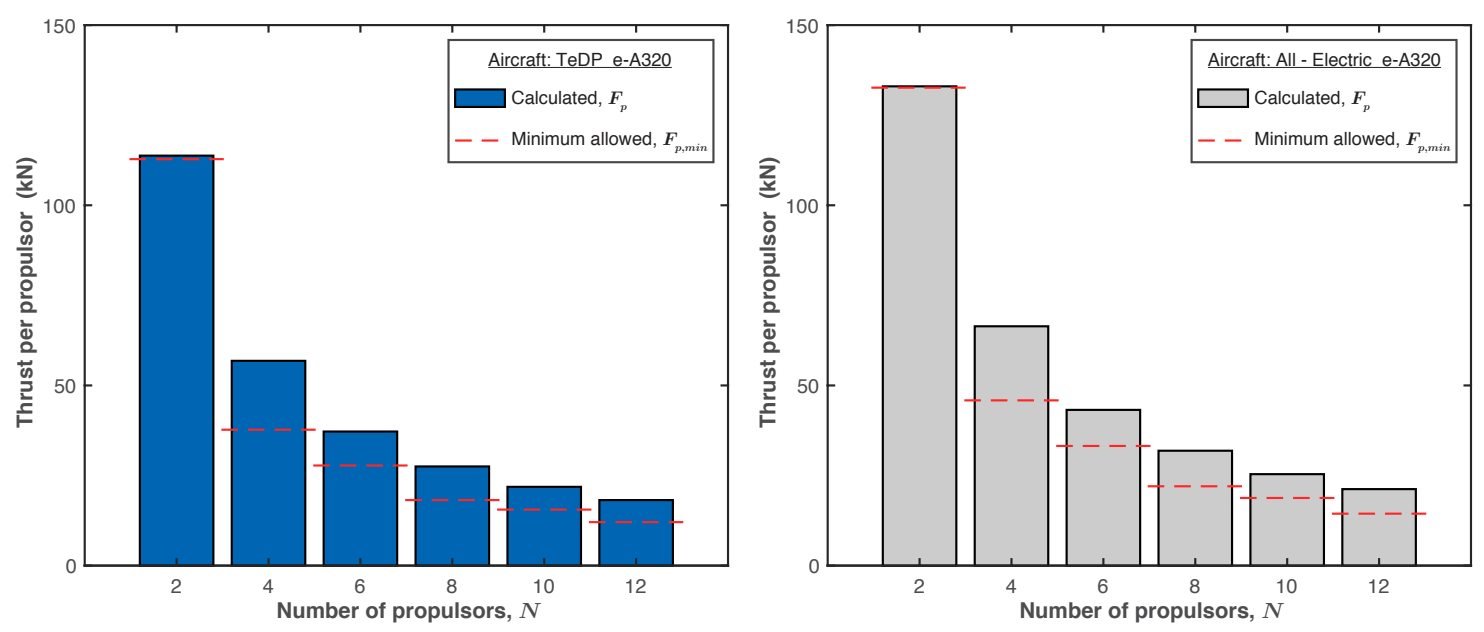

Fig. 11 Takeoff thrust per propulsor of the e-A320 variations for different number of propulsors. The dashed red lines signify the minimum thrust per propulsor as governed by safety demands.

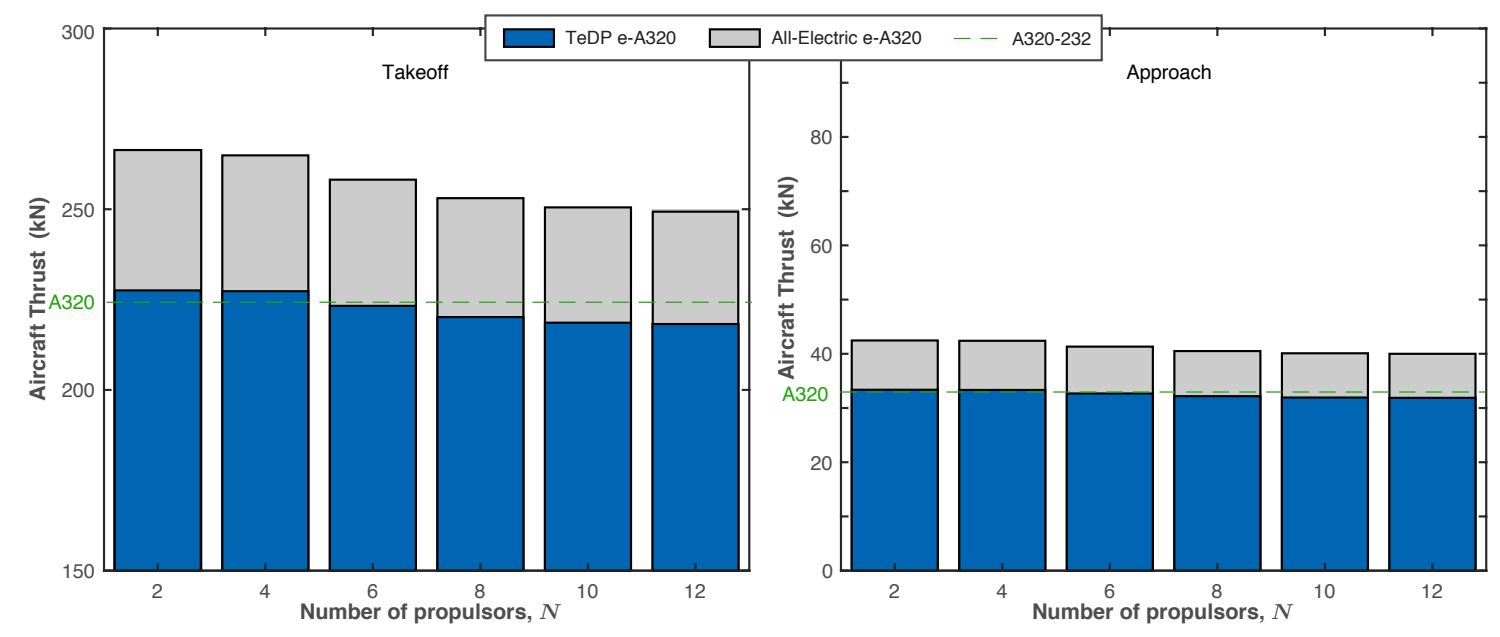

Fig. 12 Thrust requirements of the different e-A320 variations for performing the default A320 takeoff and approach procedures. The green dashed line represents the baseline A320-232.

\section{Noise estimations for the DEP aircraft}

Having acquired thrust requirements for the e-A320s, the noise at source variation with propulsors' number is estimated through the framework by Synodinos et al.[18]. The effect of batteries weight is also discussed, whereas Noise-Power-Distance (NPD) curves and noise exposure contours are constructed.

\section{A. Noise at source}

Figure 13 depicts the PWL difference between the baseline A320-232 and the e-A320s for takeoff and approach. Propulsors' noise varies according to variations of thrust and propulsors' number and characteristics, whereas airframe noise is influenced from flap deflection angle changes. To incorporate the effect of aircraft weight variation on approach flap setting, it is conveniently assumed that flaps are deflected/retracted by one degree per supplementary/deducted ton.

At takeoff, where propulsion noise dominates, noise at source is reduced, despite the increased takeoff thrust requirements of the e-A320 demonstrated in Figure 12 This is because total airflow traversing the propulsors is larger than the airflow passing through the A320-232 turbofans, as seen in Table 1, for instance, while for the 4 propulsors e-A320 the total airflow is $4 \times 248=992 \mathrm{~kg} / \mathrm{s}$, it is only $2 \times 355=710 \mathrm{~kg} / \mathrm{s}$ for the A320-232. Hence, for the same thrust, the jet velocity and so jet noise is lower for the e-A320s than for the A320-232; apparently, the increased thrust 

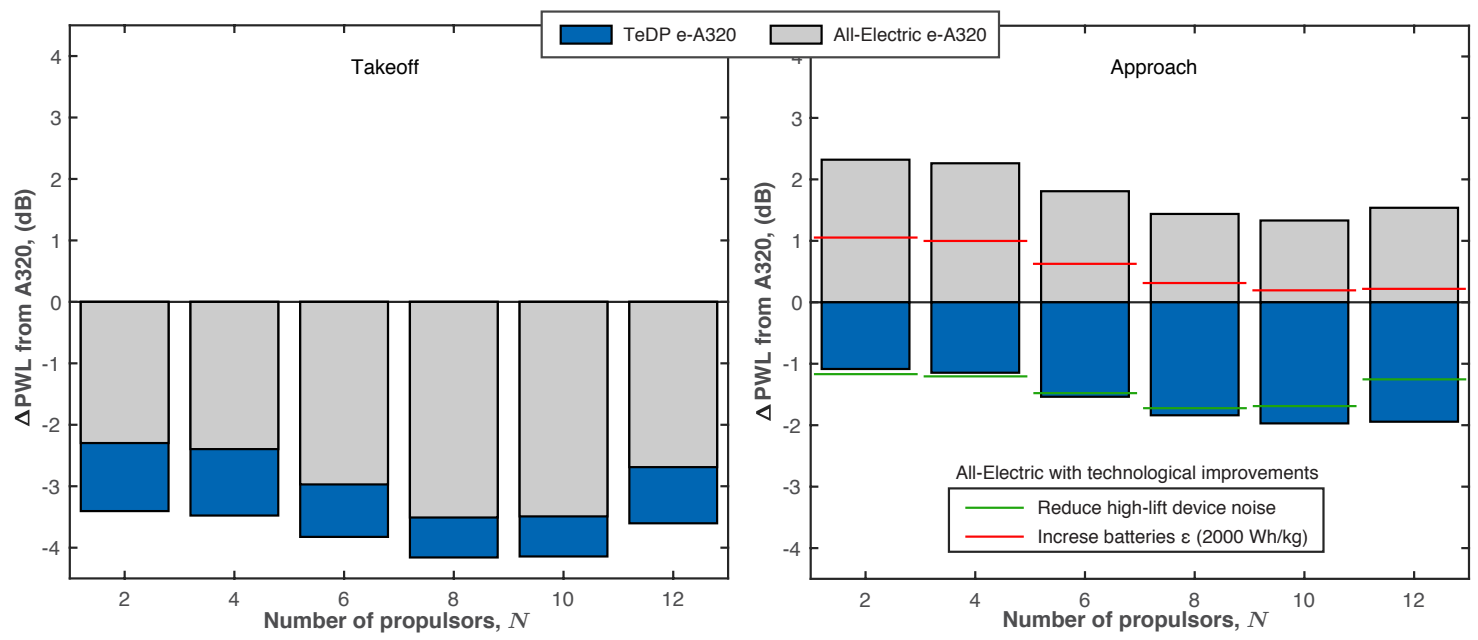

Fig. 13 Aircraft PWL difference between baseline A320-232 and the e-A320s for takeoff (left) and approach. The horizontal lines at approach depict PWL differences achievable through technological improvements.

requirements of some e-A320s is relatively small to outweigh the noise impact of this jet velocity difference.

The right plot in Figure 13 shows aircraft PWL differences at approach, where the airframe noise contribution dominates. The PWL of the TeDP e-A320s is 1-2 dB smaller than the A320 due to: a) the reduced propulsors' noise, and b) the fact that TeDP with more than 4 propulsors are lighter than the A320 (see Figure 10). The significantly heavier All-Electric e-A320s are 'noisier' than the A320-232 because, considering current technology, it is assumed that larger flap deflection angles are needed to compensate for their weight and allow them to fulfil the standard approach flight profile; airframe noise increases with flaps deflection angle. This increase significantly affects the whole aircraft noise because at approach, airframe noise prevails. Possible future technologies for reducing All-Electric aircraft approach noise are a) enhanced L/D ratio to eliminate further flap deflections, and/or b) batteries with larger specific energy density to reduce aircraft weight. Figure 13 includes the estimated noise impact of these technologies. Further noise reductions are achievable by designing quieter airframes (e-A320 aircraft in this study use the A320 airframe).

Moreover, it is interesting to notice the small PWL differences between the e-A320s of the same architecture (TeDP or All-Electric) but different propulsors' number. The maximum takeoff PWL difference, which is between the $N=2$ and $N=10$ types is $0.8 \mathrm{~dB}$ for the TeDP and $1.2 \mathrm{~dB}$ for the All-Electric e-A320 (see left plot in Figure 13). Whereas during approach, the maximum PWL difference is around $1 \mathrm{~dB}$ for both e-A320 architecture. However, as seen in the noise contour maps of Figure 17, this small PWL difference suffices to offer notable noise benefits in communities around airports.

Finally, as pointed out earlier, takeoff and/or approach flight profiles optimised for DEP aircraft may be different than the default ones and therefore community noise impact comparisons could look different than the PWL comparisons.

\section{B. Effect of batteries weight on noise}

Throughout this study it is assumed that state-of-the-art battery technologies will be capable of reaching 1500 $\mathrm{Wh} / \mathrm{kg}$ of specific energy by the target EIS year, i.e. 2035. This section examines the effect of batteries technological evolution on aircraft noise. Figure 14 plots the aircraft PWL variation at takeoff (top) and approach, for different number of propulsors and batteries with specific energy ranging from 800 to $2000 \mathrm{Wh} / \mathrm{kg}$. Agreeing with trends of Figure 13 , the minimum PWL at takeoff is located at $N=8$ and $e=1900 \mathrm{Wh} / \mathrm{kg}$, and in approach at $N=10$ and $e=2000 \mathrm{Wh} / \mathrm{kg}$.

\section{NPD curves}

A substantial feature of the framework by Synodinos et al.[18] is that it enables purely computational development of NPD curves (NPDs) that are the main input for constructing noise exposure contour maps around airports. NPDs normally derive through aircraft flyover noise measurements and are therefore only available for existing aircraft. Computationally derived NPDs provide the option of assessing community noise benefits of different strategies through noise exposure contour map sin the vicinity of airports. 

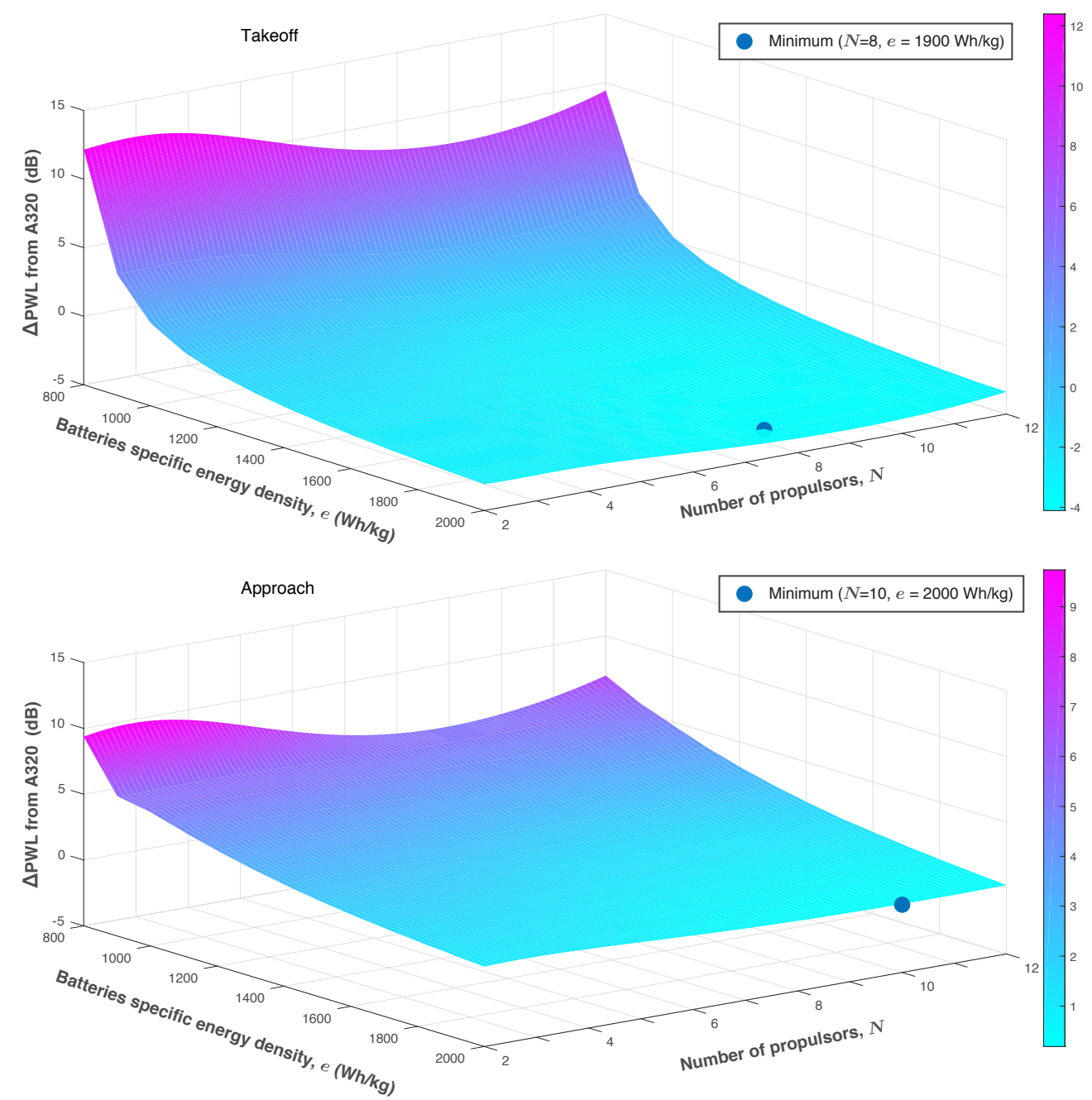

Fig. 14 e-A320s PWL difference from baseline, at takeoff (top) and approach, as a function of number of propulsors, $N$, and batteries specific energy, $e$.

As described in [18], the procedure for computing NPDs uses aircraft spectral properties, in order to account for noise propagation effects. Spectral properties are expected to vary among the examined DEP aircraft; for instance, the fan rotational speed increases with decreasing the fan diameter (and thus increasing the number of propulsors) shifting the blade-passing frequency towards higher frequencies. Thus, the tonal noise component may become more important (but at the same time more absorbable by the atmosphere). This spectral dependancy on fan diameter is approximated and incorporated in NPD calculations based on the spectral classes of existing aircraft that are available in the ANP Database [17]. More specifically, each e-A320 variant is assigned the spectral class of existing aircraft with resembling fan diameters, as summarised in Table 4. Clearly, a higher-fidelity model describing the propulsor's spectral variation with fan diameter would be advantageous.

Table 4 Turbofan engines of similar dimensions as the electric propulsors.

\begin{tabular}{lccccc} 
Propulsor fan diameter $(\mathbf{m})$ & 1.98 & 1.42 & 1.02 & 0.73 & 0.52 \\
\hline Turbofan of similar size & PW2037 & CFM56 & RR AE3007 & GE CF700 & PW625F
\end{tabular}

Figure 15 presents takeoff and approach NPD curves for the e-A320 variations, as estimated using these spectral classes and the previously estimated noise levels. The thrust values in the NPDs labels express the thrust per propulsor 
and not that of the whole aircraft (whereas noise values refer to the whole aircraft). For fixed propulsors' number, TeDP and All-Electric e-A320s have identical takeoff NPDs, whereas at approach where airframe noise prevails, NPDs are different in accordance with the assumption that these aircraft use different flap settings at descent.
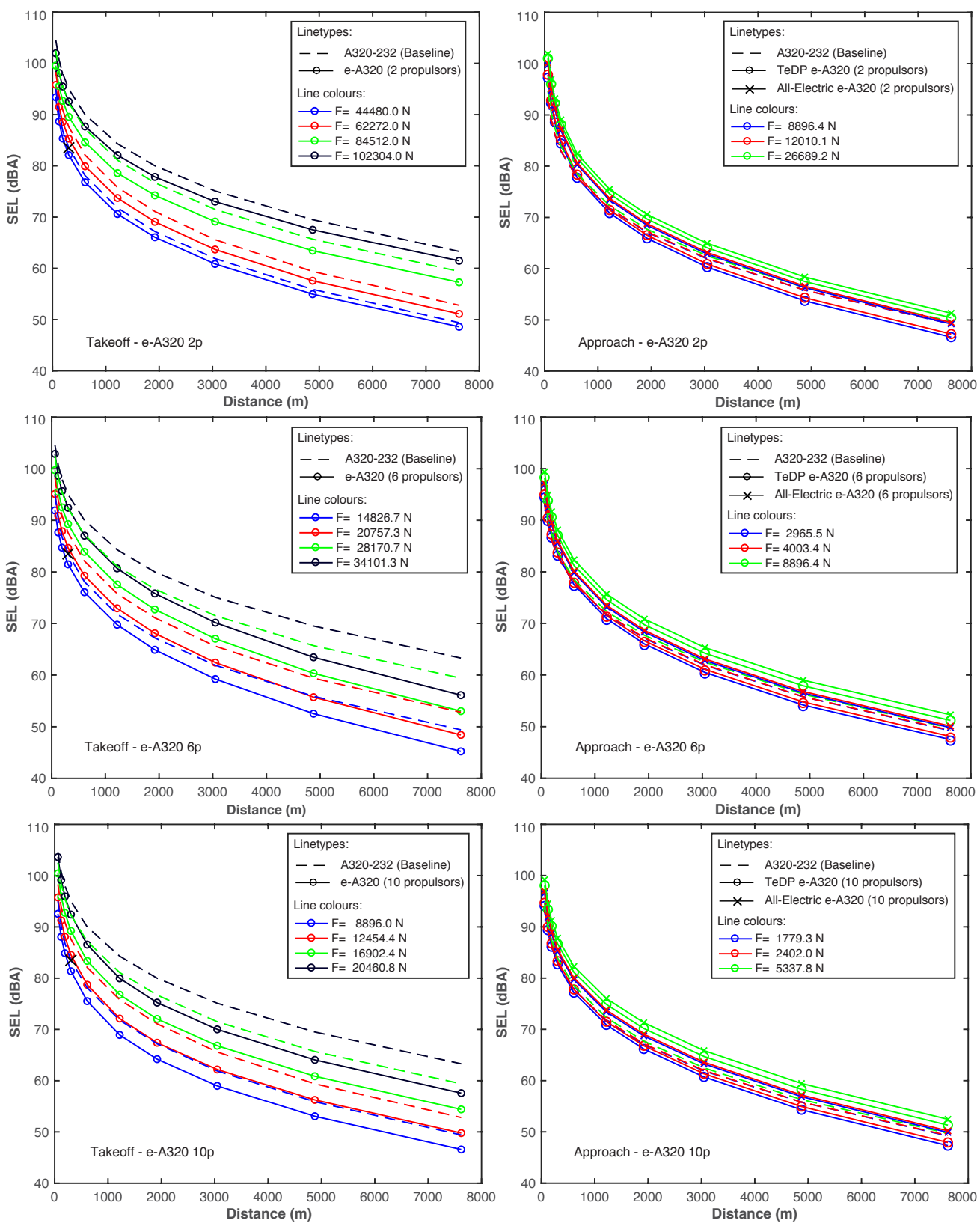

Fig. 15 Estimated takeoff and approach NPD curves for the e-A320 variations.

Comparing the takeoff NPDs for the 2 and 6 propulsors e-A320s, a noise reduction is observed that is partially justified by the smaller thrust requirements of the 6 propulsors variant (see Figure 12). Yet, the fact that this reduction increases with distance implies the influence of the different spectral classes assigned to the propulsors according to their fan diameter; noise emitted by the 6 propulsors e-A320 is likely to experience higher atmospheric attenuation. The NPDs for the 6 and 10 propulsors e-A320s are similar, suggesting smaller spectral influence. Approach NPDs are almost independent of number of propulsors, whereas agreeing with trends in Figure 13 . NPDs for the TeDP and All-Electric e-A320s are respectively slightly below and above the ones for the baseline A320. In addition, due to the airframe noise dominance at approach, the various spectral classes assigned to the propulsors produced negligible noise 
difference, even at large NPD distances.

\section{Noise exposure contour maps}

Figure 16 illsutrates estimated $90 \mathrm{~dB}$ SEL noise contours for the 6 propulsors e-A320s at takeoff (top plot) and approach, as acquired by introducing the respective computed NPDs into RANE airport noise model [45]. For comparison, displayed are also the associated contours for the baseline A320, implying that the e-A320s are likely to reduce residential noise exposure around airports at takeoff. In both takeoff and approach procedures the heavier (due to batteries' weight) All-Electric e-A320 is 'noisier' than the TeDP, because it requires more thrust for realising the default A320 flight profiles, generating more propulsive noise. In fact, at approach it shows a larger noise exposure impact that the baseline A320.

Figure 17 demonstrates the effect of propulsors' number on noise contour areas for both e-A320 architectures, at takeoff (top plots) and approach. Contour areas tend to shrink with increasing the number of propulsors, as a result of the PWL variation with propulsors' number encountered in Figure 13 Exposed area differences are smaller at approach in accordance with the respective NPDs in Figure 15, whereas the biggest differences are noticed in the takeoff contours for the All-Electric e-A320s.
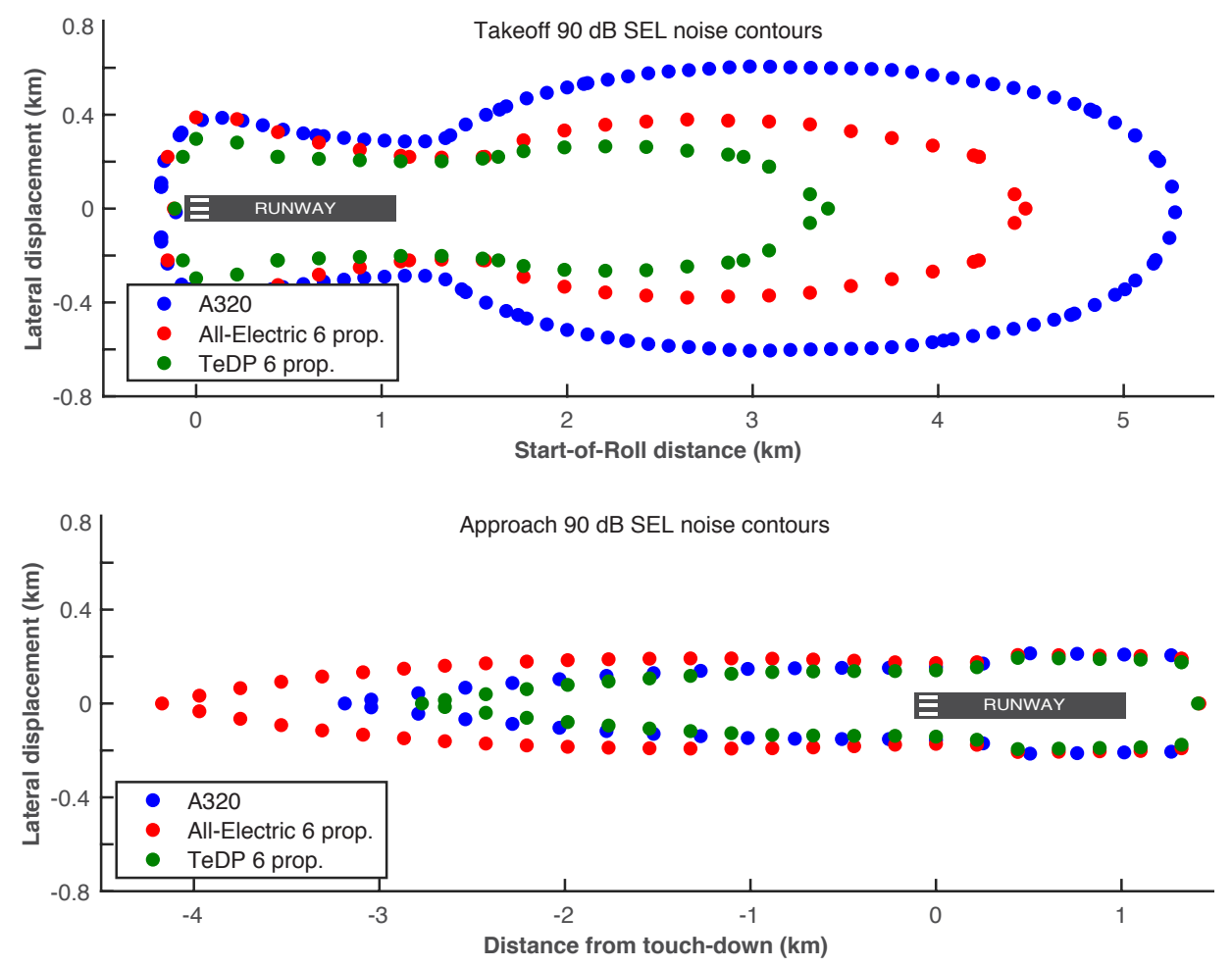

Fig. 16 Comparison of estimated takeoff (top) and approach $90 \mathrm{~dB}$ SEL contours for 6-propulsors e-A320s and contours for the baseline A320, as obtained with INM [46].

\section{Discussion and conclusions}

This paper presented and discussed preliminary noise estimations for TeDP and All-Electric tube-and-wing aircraft using the conventional A320 airframe along with various Distributed Electric Propulsion (DEP) architectures. Noise estimations were performed through the noise prediction framework for novel aircraft by Synodinos et al.[18]. Using various methodologies, assumptions and approximations, all inputs (e.g. aircraft weight breakdown and thrust requirements) to that framework were estimated, allowing not only to capture noise-related trends, but also to reveal and discuss important considerations (including safety-related ones) relevant to the transition from conventional to electric propulsion.

At this early stage of electric aircraft development when design and performance technologies are under research, 

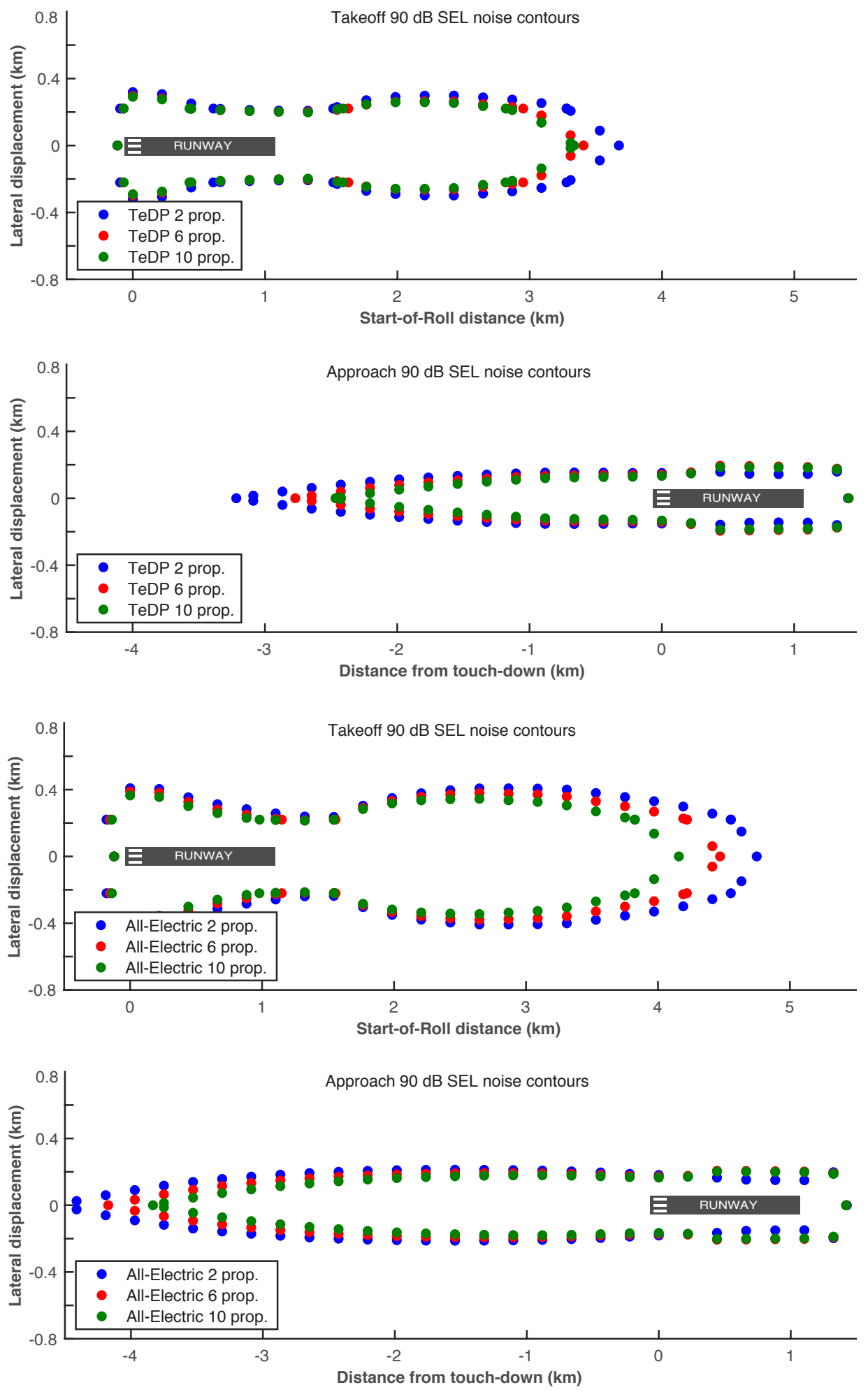

Fig. 17 Estimated takeoff and approach $90 \mathrm{~dB}$ SEL contours for the 2, 6 and 10 propulsors TeDP (top) and All-Electric e-A320s. 
assumptions and approximations are inevitable. But most importantly, trends and transition considerations, like the ones presented in this paper, are crucial for deciding which concepts and technologies, among ample emerging worldwide, are likely to satisfy future targets. Clearly, a more accurate approach would require a multi-disciplinary optimisation process, involving, among others, monetary, engineering, environmental and customer-related disciplines. Mission characteristics (e.g. range, cruise altitude) would also be optimised accordingly.

Noise impact of the examined DEP aircraft were presented in different noise metrics, including PWL, NPD curves and noise contours maps, demonstrating potential noise benefits of DEP aircraft, especially at takeoff. The effect of propulsors' number and batteries weight was highlighted. Noise could have been overestimated due to the fact that any gearbox effects on fan speed were neglected, while errors on estimated NPD curves could arise from the assumed relationship between frequency variation with propulsors' size. Also, based on published studies, the electric motor noise contribution and the propulsors' size influence on aircraft drag were assumed negligible.

Another point to consider is that the SAE-AIR1845A procedure [25], which was used to estimate e-A320 performance parameters is empirically established based on conventional engine types. However, while turbofans generate thrust from both fan and jet (i.e. the turbofan's core), thrust in electric propulsors is purely obtained from the fan, and hence thrust requirements and hence propulsive noise may have been underestimated. Moreover, thrust requirements, as well as power demands for the e-A320s were calculated based on current technology levels and the default A320 takeoff and landing profiles. Technological improvements (e.g. propulsive efficiency advances using BLI and advanced fans, development of quieter airframes, lighter materials and more efficient batteries), along with design changes (e.g. BWB designs that could offer both performance benefits and propulsors' noise shielding) and operational modifications (e.g. steeper approach/takeoff profiles, climb at slower velocity) may lead to additional noise reductions.

\section{References}

[1] European Environment Agency (EEA)- European Aviation Safety Agency (EASA) - Eurocontrol, "European aviation environmental report 2016," , 2016. URL http://ec. europa.eu/transport/sites/transport/files/modes/air/ aviation-strategy/documents/european-aviation-environmental-report-2016-72dpi.pdf.

[2] "Global Climate Change. Vital Signs of the Planet.", 2015. URL http://climate.nasa.gov

[3] European Commission (EC), "Flightpath 2050 Europe's Vision for Aviation," Tech. rep., Report of the High-Level Group on Aviation Research, Luxembourg, 2011.

[4] Ashcraft, S. W., Padron, A. S., Pascioni, K. A., Stout, J., Gary W., and Huff, D. L., "Review of Propulsion Technologies for N+3 Subsonic Vehicle Concepts," Tech. Rep. NASA/TM-2011-217239, NASA Glenn Research Center, Cleveland, OH, United States, 2011.

[5] Rizzi, S. A., Palumbo, D. L., Rathsam, J., Christian, A. W., and Rafaelof, M., "Annoyance to Noise Produced by a Distributed Electric Propulsion High-Lift System,” 23rd AIAA/CEAS Aeroacoustics Conference, Denver, Colorado, 2017. doi:doi.org/10.2514/6.2017-4050.

[6] Felder, J. L., Kim, H. D., and Brown, G. V., “Turboelectric Distributed Propulsion Engine Cycle Analysis for Hybrid-Wing-Body Aircraft," 47th AIAA Aerospace Sciences Meeting including The New Horizons Forum and Aerospace Exposition, Orlando, Florida, 2009. doi:doi:10.2514/6.2009-1132.

[7] Wick, A. T., Hooker, J. R., and Hardin, C. J., "Integrated Aerodynamic Benefits of Distributed Propulsion," 53rd AIAA Aerospace Sciences Meeting, Kissimmee, Florida, USA, 2015.

[8] Arntz, A., and Atinault, O., "Exergy-Based Performance Assessment of a Blended Wing-Body with Boundary-Layer Ingestion," AIAA Journal, Vol. 53, No. 12, 2015, pp. 3766-3776. doi:10.2514/1.J054072.

[9] Hornung, M., Isikveren, A. T., Cole, M., and Sizmann, A., "Ce-Liner - Case Study for eMobility in Air Transportation,” 2013 Aviation Technology, Integration, and Operations Conference, Los Angeles, CA, USA, 2013. doi:http://dx.doi.org/10.2514/6. 2013-4302.

[10] Isikveren, A. T., Seitz, A., Bijewitz, J., Mirzoyan, A., Isyanov, A., Grenon, R., Atinault, O., Godard, J.-L., and Stückl, S., "Distributed Propulsion and Ultra-high By-pass Rotor Study at Aircraft Level," The Aeronautical Journal, Vol. 119, No. 1221, 2015, pp. 1327-1376. doi:10.1017/S0001924000011295.

[11] Schiltgen, B., Green, M., Gibson, A., Hall, D., Cummings, D., and Hange, C., "Benefits and Concerns of Hybrid Electric Distributed Propulsion with Conventional Electric Machines," 48th AIAA/ASME/SAE/ASEE Joint Propulsion Conference \& Exhibit, Atlanta, Georgia, 2012. doi:doi:10.2514/6.2012-3769. 
[12] Bradley, M. K., and Droney, C. K., "Subsonic Ultra Green Aircraft Research: Phase I Final Report," Tech. Rep. NASA/CR2011-216847, NASA, 2011.

[13] "EASA Type Certificates (TCDS)," , 2017. URL https://www.easa.europa.eu/document-library/typecertificates

[14] “Jet Engine Specification Database,", 2005. URL http://www . jet-engine.net

[15] Filippone, A., Advanced Aircraft Flight Performance, Cambridge University Press, 2012.

[16] Kroo, I., and Shevell, R., Aircraft Design: Synthesis and Analysis, Desktop Aeronautics, Stanford (online version, available at: http://adg.stanford.edu/aa241/AircraftDesign.html), 2017.

[17] Eurocontrol Experimental Centre, "Aircraft Noise and Performance (ANP) Database v2.1," , 2016. URL http://www. aircraftnoisemodel.org

[18] Synodinos, A. P., Self, R. H., and Martinez, A. J., "Framework for Predicting Noise-Power-Distance Curves for Novel Aircraft Designs," Journal of Aircraft, Vol. Ahead of Print, 2017, pp. 1-11.

[19] Heidmann, M. F., “Interim prediction method for fan and compressor source noise,” Tech. Rep. NASA-TM-X-71763, NASA Lewis Research Center, Cleveland, OH, United States, 1979.

[20] Guo, Y., Burley, C. L., and Thomas, R. H., "Modeling and prediction of krueger device noise," 22nd AIAA/CEAS Aeroacoustics Conference, American Institute of Aeronautics and Astronautics Inc, AIAA, 2016. doi:10.2514/6.2016-2957.

[21] Huff, D. L., Henderson, B. S., and Envia, E., "A First Look at Electric Motor Noise For Future Propulsion Systems," Oral/Visual Presentation GRC-E-DAA-TN31506, NASA Glenn Research Center; Cleveland, OH, United States, April 2016.

[22] Fink, M. R., “Airframe Noise Prediction Method,” Tech. Rep. FAA-RD-77-29, Federal Aviation Administration, 1977.

[23] Lighthill, M. J., “On Sound Generated Aerodynamically. I. General Theory,” Proceedings of the Royal Society of London A: Mathematical, Physical and Engineering Sciences, Vol. 211, No. 1107, 1952, pp. 564-587. doi:10.1098/rspa.1952.0060, URL http://rspa.royalsocietypublishing.org/content/211/1107/564

[24] "Airworthiness Standards: Transport Category Airplanes, Federal Aviation Administration Regulations, Title 14, Part 25 (FAR 25),", January 2017. URL http://www.ecfr.gov

[25] "Procedure for the Calculation of Aircraft Noise in the Vicinity of Airports," Tech. Rep. Aerospace Information Report - SAE AIR1845A, SAE International, Issued 1986, Revised 2012.

[26] Gregorio, F. D., Steiling, D., Benini, E., and Ponza, R., "ERICA tiltrotor airframe wake characterization," Proceedings of the 41st European Rotorcraft Forum, Munich, Germany, 2015.

[27] Jobe, C. E., "Prediction of Aerodynamic Drag," Tech. Rep. AFWAL - TM-84-203, Flight Dynamics Laboratory, Air Force Wright Aeronautical Laboratories, Ohio, United States, 1984.

[28] “Aircraft Technical Data and Specifications,", 2017. URL http://www.airliners.net/aircraft-data/

[29] ICAO, "Agenda Item 1: Civil aviation statistics - ICAO classification and definition. Available capacity and average passenger mass." 10th Session of the statistics division, Montréal, Canada, 2009.

[30] Torenbeek, E., “The initial calculation of range and mission fuel during conceptual design,” Tech. Rep. LR-525, Delft University of Technology, Faculty of Aerospace Engineering, 1987.

[31] Cumpsty, N. A., Jet Propulsion: A Simple Guide to the Aerodynamics and Thermodynamic Design and Performance of Jet Engines simple guide to the aerodynamics and thermodynamic design and performance of jet engines, $2^{\text {nd }}$ ed., Cambridge University Press, 2003.

[32] International Standards and Recommended Practices, Annex 6 - Operation Of Aircraft, International Civil Aviation Organization (ICAO), 2016.

[33] European Aviation Safety Agency EASA, "ICAO Aircraft Engine Emissions Databank,", 2014. URL http://easa. europa. eu/document-library/icao-aircraft-engine-emissions-databank.

[34] Lolis, P., Giannakakis, P., Sethi, V., Jackson, A. J. B., and Pilidis, P., "Evaluation of aero gas turbine preliminary weight estimation methods," Aeronautical Journal, Vol. 118, No. 1204, 2014, pp. 625-641. 
[35] Liu, C., Si, X., Teng, J., and Ihiabe, D., "Method to Explore the Design Space of a Turbo-Electric Distributed Propulsion System," Journal of Aerospace Engineering, Vol. 29, No. 5, 2016.

[36] Sagerser, D. A., Lieblein, S., and Krebs, R. P., "Empirical expressions for estimating length and weight of axial-flow components of VTOL powerplants,” Tech. Rep. NASA-TM-X-2406, NASA Lewis Research Center, Cleveland, OH, United States, 1971.

[37] Raymer, D. P., Aircraft Design a Conceptual Approach, 5th ed., American Institute of Aeronautics \& Astronautics (AIAA), 2012.

[38] Huff, D. L., "Noise Reduction Technologies for Turbofan Engines,” Tech. Rep. NASA-TM-214495, NASA, Cleveland, Ohio 44135, 2007.

[39] Welstead, J., and Felder, J. L., "Conceptual Design of a Single-Aisle Turboelectric Commercial Transport with Fuselage Boundary Layer Ingestion,” 54th AIAA Aerospace Sciences Meeting, San Diego, California, USA, 2016.

[40] Hepperle, M., "Electric Flight-Potential and Limitations,” NPU-DLR Workshop, Braunschweig, 2014.

[41] Felder, J. L., "NASA N3-X with Turboelectric Distributed Propulsion," Presentation for the NASA Fixed Wing Project NASA Glenn Research Center, Cleveland, Ohio, 2009.

[42] Pornet, C., and Isikveren, A., "Conceptual design of hybrid-electric transport aircraft," Progress in Aerospace Sciences, Vol. 79, 2015, pp. 114 - 135. doi:http://dx.doi.org/10.1016/j.paerosci.2015.09.002.

[43] Mehta, V. K., and Mehta, R., Basic Electrical Engineering, S. Chand \& Co Ltd, 2017.

[44] Waters, M. H., and Schairer, E. T., "Analysis of turbofan propulsion system weight and dimensions," Tech. Rep. NASA-TM-X73199, NASA Ames Research Center; Moffett Field, CA, United States, 1977.

[45] Torija, A. J., Self, R. H., and Flindell, I. H., "A model for the rapid assessment of the impact of aviation noise near airports," The Journal of the Acoustical Society of America, Vol. 141, No. 2, 2017, pp. 981-995. doi:10.1121/1.4976053.

[46] Boeker, E. R., Dinges, E., He, B., Fleming, G., Roof, C. J., Gerbi, P. J., Rapoza, A. S., and Hemann, J., "Integrated Noise Model (INM) Version 7.0 Technical Manual,” Tech. Rep. FAA-AEE-08-01, Federal Aviation Administration, Washington, D.C., January 2008. 